\title{
Interaction of atopy and exposure to cotton dust in the bronchoconstrictor response* $\uparrow$
}

\author{
R N JONES, B T BUTCHER, Y Y HAMMAD, J E DIEM, H W GLINDMEYER, III, \\ S B LEHRER, J M HUGHES, AND H WEILL
}

From the Pulmonary Diseases and Clinical Immunology Sections, Tulane University School of Medicine, New Orleans, Louisiana 70112, USA

\begin{abstract}
A survey of 255 workers in four cottonseed crushing mills included a respiratory health questionnaire, allergy skin testing, and measurements of lung function over the Monday working shift. Atopy was defined as having two or more positive weal reactions to common inhalant antigens. Categories of exposure to dust were based on the stage of milling, and one category contained workers with continuous exposure to cotton dust derived from linters, the cotton fibres adherent to cottonseed. Atopy and exposure to dust were found to have significant interaction: large mean declines in $\mathrm{FEV}_{1}$ and $\mathrm{FEF}_{25-75}$ occurred only in the workers exposed to linter dust who were also atopic. Skin-testing surveys in cotton textile mills have concentrated on specific cotton antigen reactivity and its first-order relations to symptoms. Our results indicate a need to identify atopic workers, and to search for interactions between atopy and other variables that may influence acute changes in expiratory flow rates.
\end{abstract}

One of the characteristic responses to cotton dust aerosols is an acute decline, over the working shift, in maximal expiratory flow rates. ${ }^{1}$ This decline is largest on Monday and may disappear later in the working week. The similarity to the temporal pattern of symptoms of byssinosis, and the prevalence of postshift functional declines in the cotton textile industry, imply that the acute bronchoconstrictor effect identifies people at risk of developing chronic airways obstruction.

The operations of cottonseed crushing mills produce complex and often heavy exposure to dusts, including aerosols of cotton linters contaminated with bracts and other rubbish. ${ }^{2-5}$ In a recent survey of respiratory health in this industry we found a significant interaction of atopy and linter dust exposure on the acute decline in expiratory flow rates.

*Supported by a grant (HL 15092-06) from the National Heart, Lung, and Blood Institute, National Institutes of Health, US Department of Health, Education, and Welfare.

+Presented in part at the annual meeting of the American Thoracic Society, 14-17 May 1978, Boston, Massachusetts.

Requests for reprints should be addressed to Dr Robert $\mathrm{N}$ Jones, 1700 Perdido Street, New Orleans, Louisiana, 70112.

Received 10 May 1979

Accepted 4 September 1979

\section{Materials and methods}

Four cottonseed crushing mills in the Southern United States were visited in 1977. Area dust levels were measured by methods specified in the NIOSH cotton standard criteria document using the Lumsden-Lynch vertical elutriator. ${ }^{6}$ Simultaneous collection of a total dust area sample was accomplished by drawing air across an open-face filter at 2.6-3.2 $1 / \mathrm{min}$. Personal levels of total dust exposure were estimated by sampling with portable, batterypowered pumps connected to filters worn at the collar level.

Since the composition of cottonseed mill dust is strongly affected by the step of processing, ${ }^{34}$ categories of exposure were defined by the sources of dust, and by the time each worker spent in proximity to the sources. The "linter dust" category included workers continuously exposed to linter dust in such operations as seed feeding, cleaning, delinting, lint baling, and hulling. The "products dust" category included workers continuously exposed to other types of dust in oil extraction, cake and meal preparation, hull and meal sacking and loading, or boiler room operations. The "mixed dust" category included workers exposed to both types of dust.

The British MRC questionnaire, modified for 
detection of byssinosis, was administered by a trained interviewer. Questionnaire responses were analysed for the prevalence of byssinosis (by the Schilling definition and an expanded definition described below), chronic bronchitis, atopy, dyspnoea, and groups of upper and lower respiratory symptoms.

Lung function measurements were performed before work on a day after at least $\mathbf{3 6}$ hours (usually more than 40) away from the mill. Spirometric tests were performed using a dry, rolling-seal spirometer, the output from which was displayed as volume-time and flow-volume plots of the maximal forced expiratory vital capacity manoeuvre. The tests recorded for analysis included the seven-second forced expiratory volume (FVC), forced expiratory volume in one second $\left(F E V_{1}\right)$, forced expiratory flow over $25-75 \%$ of FVC $\left(\mathrm{FEF}_{25-75}\right)$, the ratio of $\mathrm{FEV}_{1}$ to $\mathrm{FVC}$, and the FEF rates at $50 \%\left(\mathrm{FEF}_{50}\right)$ and $25 \%\left(\mathrm{FEF}_{25}\right)$ above residual volume. Four or five maximal expirations were performed at each session, and mean test values were taken from the two expirations yielding the largest FVC values, with the added requirement that the FVC values differed by not more than $3 \%$. If more than two expirations met these requirements the mean test values were taken from the two expirations yielding the largest combined $\mathrm{FEV}_{0.5}$ (sensitive to initial effort) and $\mathrm{FEF}_{25-75}$ (sensitive to sustained effort).

Spirometric tests were repeated on the same day near the end of each worker's shift. Results of testing at the second session are referred to as "postshift" values. For comparison of preshift ("baseline") and postshift values of $\mathrm{FEF}_{25-75}, \mathrm{FEF}_{50}$, and $\mathrm{FEF}_{25}$, "iso-volume" correction was applied, taking the flow rates from the appropriate points derived from the largest FVC. Comparisons were made by subtracting preshift from postshift values, so declines appear as negative numbers.

Allergy skin testing was performed with 10 common inhalant allergens, and with saline extracts of homogenised whole cottonseed and cottonseed linters from each individual mill. The prick testing method was used, and a positive immediate reaction was defined as a weal two or more millimetres in diameter larger than the saline control.

\section{Results}

Figure 1 shows the mean total and mean elutriated dust levels of the air samples from the linter dust areas of the four cottonseed mills. The number of these area samples ranged from 43 in mill I to 60 in mill III. The observed levels are high in relation to the permissible exposure limit of $0.5 \mathrm{mg}$ of elutriated

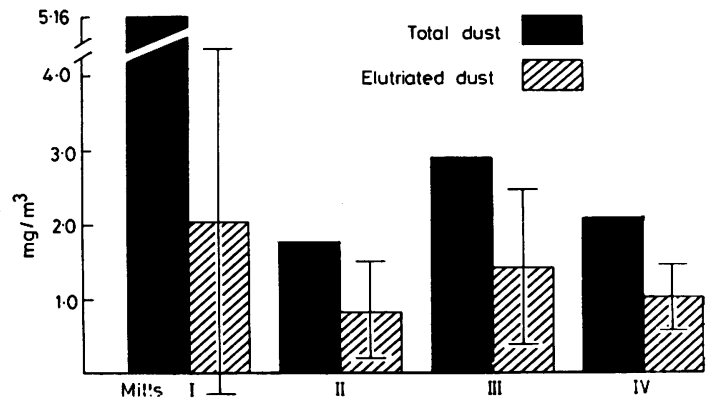

Fig 1 Mean dust levels $\left(\mathrm{mg} / \mathrm{m}^{3}\right)$ in four cottonseed crushing mills, obtained by area sampling. Standard deviations are shown for samples collected with the vertical elutriator.

dust per cubic metre recently promulgated by the US Department of Labor.?

The target study population consisted of all 334 employees of the four mills; information supplied by the mills indicate that $98 \%$ were male, $66 \%$ black, and that 36,31 , and $33 \%$ were employed in the linter, mixed, and products dust categories, respectively. The mean age was 38.7 years $(S D \pm 13.5)$ and the mean length of work in the cottonseed mills was $9 \cdot 8$ years ( $\mathrm{SD} \pm 10 \cdot 8)$. Mean age and length in the mill were largest in the products dust group (40.5 and 12.5 years, respectively). Thirty-five employees did not work on the day of testing and four were disqualified for having worked in the mill on the day before; attempts were made to enlist the remaining 295 into the study.

Interviews were obtained with $256(87 \%)$ of these employees; those interviewed were $97 \%$ male and $63 \%$ black; 38,28 , and $34 \%$ were employed in the linter, mixed and products dust categories, respectively. The mean age was $38 \cdot 1$ years (SD $\pm 13 \cdot 7$ ) and the mean length of work in the cottonseed mills was 9.9 years (SD \pm 10.9 ); these means were largest in the products dust group (41.4 and 13.0 years, respectively). With respect to sex, race, age, and duration and area of employment, the interviewed employees thus constitute a representative subset of the target population.

Of those interviewed, $52 \%$ were current cigarette smokers and $20 \%$ ex-cigarette smokers, with similar rates in the three dust categories. The overall prevalence of byssinosis was $1.6 \%$ (four of 256 ) using the symptoms of chest tightness or difficulty in breathing in the criteria propounded by Schilling et $a .^{8}$ In order not to miss possibly equivalent symptoms we also applied an expanded definition that accepted any lower respiratory symptom with the characteristic periodicity - that is, initially present only on Mondays, or improving later in the working 
week. By the expanded definition, the overall prevalence was $4.7 \%(12 / 256)$. These rates of byssinosis are lower than those usually found in cotton textile mills. ${ }^{9-11}$ The overall prevalence of chronic bronchitis (productive cough for three consecutive months of at least the past two years) was $7.5 \%$, a rate that is also lower than those found in many working populations. From interview responses, $38 \%$ were considered atopic; the definition included asthma, hay fever, or atopic dermatitis (by name), or symptom patterns suggestive of one or more of those conditions. Atopic individuals and those with byssinosis or chronic bronchitis were distributed rather equally among the three dust exposure groups, as were dyspnoea (breathlessness when hurrying along level ground or walking up a mild incline) and all lower respiratory symptoms gathered into a single response variable. The only significant difference between rates for the different categories of exposure was for upper respiratory symptoms, where a significantly lower prevalence was found in workers in the linter dust category.

Allergy skin testing was completed on $\mathbf{2 3 0}$ of those interviewed. The rates of reactivity to skin testing, by exposure group, are shown for each antigen (fig 2). Linter and (whole) cottonseed antigen reactivity rates are greatest in the linter exposure gloup, less in the mixed dust group, and least in the products dust group. Only fusarium, among the other antigens, shows comparable excess reactivity in the linter group; this fungus is said to be a common contaminant of raw cotton fibre. ${ }^{12}$

Despite different rates for various antigens, the overall rates of skin test reactivity were similar in the three exposure groups. Defining skin-test atopy as having positive skin test reactions to two or more common inhalants (excluding linter and cottonseed antigens), similar prevalences were found

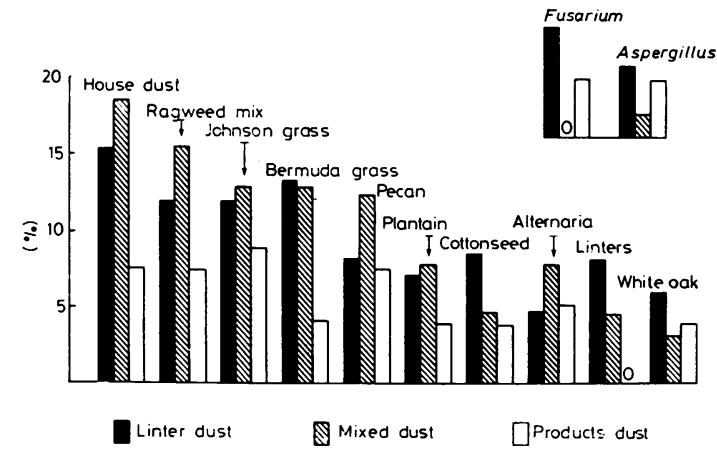

Fig 2 Skin test reactivity rates, by dust exposure category, for 10 common inhalant and two workplace antigens. in all categories $(15 \cdot 3,16.9$, and $12.5 \%)$, with an overall rate of $15 \%$.

Although there was an association between interview atopy and skin-test atopy, classification as atopic by interview responses was not a good predictor of skin-test atopy: $75 \%$ of those judged atopic by interview were not atopic by skin test and $8 \%$ who were non-atopic by interview were atopic by skin test.

Comparing the 34 individuals thus defined to be skin-test atopic with the 196 who were not (there were 20 individuals with a positive reaction to only one common inhalant), there were no significant differences in cigarette smoking or prevalence rates of the various symptoms. The means of all three dust measurements and length of employment in mill were almost identical for the two groups; the atopics were, on the average, younger than the non-atopics ( 34 versus 38 years), although the difference was not significant.

Valid preshift and postshift lung function measurements were obtained for 167 of the interviewed individuals; the remaining 89 subjects either performed the necessary spirometric manoeuvres inadequately or failed to appear for testing one or both times.

Of the 167 with complete spirometry, 68,49 , and 50 individuals $(41,29$, and $30 \%)$ were in the linter, mixed, and products dust categories, respectively; this distribution is quite similar to those of both the target and interviewed populations.

Comparisons were made of the 167 individuals with complete spirometry and the 89 without; these comparisons included all demographic variables, symptomatology, and smoking habits. No differences were observed except for the mean age of those in the mixed dust category (a mean of 35 years for those in this category with complete spirometry versus a mean of $\mathbf{4 3}$ years for those without) and the mean duration of employment in the mills for those in the linter category (seven years for those in this category with complete spirometry versus 13 years for those without).

For those with complete spirometry, there was no difference in symptom rates among the three dust categories except for upper respiratory symptoms, for which the prevalence was significanlty lower in the linter group. Among these 167, percentages of cigarette smokers were also similar for the three categories. Mean age and mean length in mill were again largest in the products dust group (41.4 and $13 \cdot 1$ years, respectively).

Each individual was assigned three measures of dust exposure (area total dust, area elutriated dust, personal total dust) based on the air sampling procedures described above. Mean and median dust 
Table 1 Dust levels $\left(\mathrm{mg} / \mathrm{m}^{3}\right)$ by dust type category

\begin{tabular}{|c|c|c|c|c|c|c|c|c|c|}
\hline \multirow[t]{2}{*}{ Statistic } & \multicolumn{3}{|c|}{ Total dust (area sampling) } & \multicolumn{3}{|c|}{ Elutriated dust (area sampling) } & \multicolumn{3}{|c|}{ Total dust (personal sumpling) } \\
\hline & Linter & Mixed & Products & Linter & Mixed & Products & Linter & Mixed & Products \\
\hline \multirow{3}{*}{$\begin{array}{l}\text { Mean } \\
\text { Median } \\
\text { Standard } \\
\text { deviation }\end{array}$} & $3 \cdot 07$ & $2 \cdot 60$ & $4 \cdot 42$ & $1 \cdot 63$ & $1 \cdot 30$ & $2 \cdot 20$ & $6 \cdot 35$ & $2 \cdot 60$ & $4 \cdot 87$ \\
\hline & $2 \cdot 42$ & $1 \cdot 61$ & 0.66 & $1 \cdot 21$ & 0.81 & 0.33 & $3 \cdot 13$ & $1 \cdot 61$ & 0.67 \\
\hline & $2 \cdot 46$ & $2 \cdot 53$ & $12 \cdot 26$ & $1 \cdot 26$ & $1 \cdot 26$ & $6 \cdot 14$ & $9 \cdot 27$ & $2 \cdot 53$ & $12 \cdot 28$ \\
\hline
\end{tabular}

exposures (over individuals) were then calculated for the linter, mixed, and products dust workers (table 1). None of the differences in means or medians across dust categories was significant.

Baseline or preshift lung function testing showed overall mean values of $\mathrm{FVC}=106.4 \%$ predicted, $\mathrm{FEV}_{1}=102.22 \%$ predicted, and $\mathrm{FEF}_{25-75}=86.6 \%$ predicted. The mean values for the linter, mixed, and products dust groups were almost identical. The predicted values for each subject's age, sex, race, and height come from standard equations. ${ }^{13-15}$

Figure 3 shows the mean declines in lung function over the working shift. Except for the FVC (which is not a true flow rate) the largest mean declines were observed in the linter dust group. These differences among exposure group means were not significant ( $p>0.15$ for all tests); these means were also compared while adjusting for each of the dust measurements (by analysis of covariance) but the differences were again not significant $(p>0.20$ for all tests). The proportions with large declines in each exposure category were also compared: a significant relation $(p=0.05)$ to exposure was found for one test, the $\mathrm{FEV}_{1}$, with $31 \%$ in the linter dust group showing large declines (more than $150 \mathrm{ml}$ ), compared to $14 \%$ and $16 \%$ in the mixed and products dusts groups, respectively.
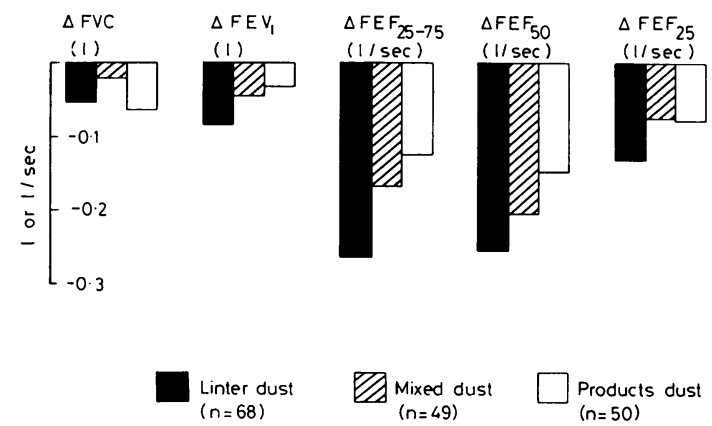

Products dust $(n=50)$

Fig 3 Mean differences, by dust-exposure category, between tests obtained before work and after at least four hours of work. Negative values denote declines during working shift.
Acute declines in expiratory flow rates were not significantly influenced by smoking habit. There were no correlations between any of the lung function changes and the number of hours between tests. The mean hours between tests were $7 \cdot 1,6 \cdot 7$, and $7 \cdot 0$ for the linter, mixed, and products groups, respectively.

There were 157 individuals who had both complete spirometry and skin testing; similar prevalences of skin-test atopy were found in all dust categories: $14.8 \%$ in linter $(9 / 61), 16.7 \%$ in mixed $(8 / 48)$, and $14.6 \%$ in products $(7 / 48)$.

Comparisons of the six atopy-dust categories showed that the non-atopic products workers had greater mean age ( 41.3 years) and mean length in mill (13.2 years) than the other groups (overall means of 36.4 and 8.7). Within each dust type category the medians of all three dust measurements were essentially identical for the atopic and non-atopic subjects; this was also true of the means within the mixed and products dust categories. A single atopic individual with a very high dust exposure was responsible for a non-significant $(p>0 \cdot 20)$ difference between mean exposures for atopic and non-atopic subjects in the linter category. This individual had one of the smaller postshift declines in ventilatory flow, a circumstance that provides further assurance that differences in measured dust concentrations were not responsible for the observed differences in postshift declines in mean expiratory flow rates.

Figure 4 shows changes in $\mathrm{FEV}_{1}$ and $\mathrm{FEF}_{25-75}$ over the working shift, for each exposure group, subdivided by skin test results into atopic and non-atopic subjects. For both measurements, the largest mean declines are in atopic individuals in the linter category (table 2), where the mean declines are more than three times those of the other groups, suggesting an interaction between dust type and atopic state. A formal analysis of variance test ${ }^{16}$ of significance for this interaction was significant for change in $\mathrm{FEV}_{1}(\mathrm{~F}(2,151)=3.08, \mathrm{p}=0.05)$ but not for change in $F F_{25-75}(F(2,151)=2 \cdot 24$, $p=0 \cdot 11)$. To test if this interaction was a result of possible confounding between exposure category and dust level, the test of significance was performed in 


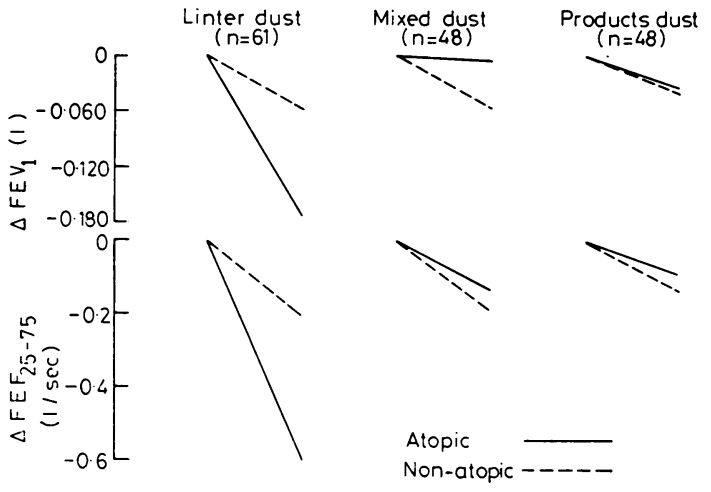

Fig 4 Declines in FEV $V_{1}$ and $F E F_{25-75}$ over working shift, by exposure category and atopy. Atopic people had two or more immediate reactions when skin tested with 10 common inhalant antigens.

an analysis of covariance model using as adjusting variables each of the six dust level variables (total, elutriated, and personal dust, as well as the logarithms of these). This adjustment had little effect on the $F$ ratios quoted above. In no case did the adjusting variable have a sta.istically significant non-zero coefficient $(p>0 \cdot 20)$. Thus for FEV there $_{1}$ is an interaction effect between atopy and dust type, and this effect is beyond any possible confounding effect due to differences in dust exposure.

Table 2 Monday workshift declines: interaction of atopy and type of dust. (Number of subjects in parentheses)

\begin{tabular}{llll}
\hline Atopy state & \multicolumn{4}{c}{ Type of dust } \\
\cline { 2 - 4 } & Linter dust & Mixed dust & Products dust \\
\hline \multicolumn{4}{c}{ Change in FEV $(1 \cdot 1)^{*}$} \\
Atopic & $-0.172(9)$ & $+0.008(8)$ & $-0.033(7)$ \\
Non-atopic & $-0.058(52)$ & $-0.057(40)$ & $-0.037(41)$ \\
Atopic & \multicolumn{4}{c}{ Change in FEF $F_{25-75}(l / s e c) \dagger$} \\
Non-atopic & $-0.600(9)$ & $-0.106(8)$ & $-0.086(7)$ \\
& $-0.200(52)$ & $-0.180(40)$ & $-0.133(41)$ \\
\hline
\end{tabular}

* $F(2,151)=3.08, p=0.05$.

$\dagger F(2,151)=2 \cdot 24, p=0 \cdot 11$.

\section{Discussion}

We recently published findings from a previous survey of respiratory health in the same cottonseed mills. ${ }^{17}$ That study also showed variable but generally high dust levels, low prevalences of byssinosis and other respiratory symptoms, and normal mean values for baseline spirometric tests. There were also mean postshift declines in expiratory flow rates on Monday, and these were significantly greater than those observed over the working shift on Friday.
The design of the present study included refined assessment of dust exposure, and skin testing for the detection of immediate hypersensitivity. The justification for basing exposure categories on the processes raising the dusts comes from studies showing the variation of composition of dusts in this industry. Fuither support comes from our observation that skin test reactivity to linters shows good correlation to categories based essentially on presumed degree of linter exposure.

The investigation of atopy might be thought speculative in view of the disappointing results of several skin testing surveys in textile mills. ${ }^{18-20}$ Most of the earlier surveys, however, were undertaken to define a causative role for allergy in byssinosis. They concentrated on antigens in mill dusts. Intradermal testing usually resulted in high rates of immediate and delayed reactions, and these rates did not correlate with disease. Our approach was less ambitious, and we used a battery of geographically common inhalants to identify the atopic subsegments of our exposure groups. Thus defined, atopy is an important variable, in interaction with linter dust, in the acute bronchoconstrictor response.

In a separate analysis the mean postshift declines in $\mathrm{FEV}_{1}$ and $\mathrm{FEF}_{25-75}$ were compared for skin test reactors and non-reactors to each of the 12 antigens used. Although linter and cottonseed antigen reactors had larger mean postshift declines than did nonreactors, four other antigens (fusarium, alternaria, Johnson grass, and Bermuda grass) had comparable utility in identifying groups with larger declines. We thus rejected the hypothesis that reactivity to the linter or cottonseed antigen had special biological significance in relation to changes in expiratory flow rates. Our conclusion is that the atopic state, rather than specific cottonseed immunoreactivity, is the important influencing variable.

Atopic people, as defined by the above methods, may possess a high degree of non-specific airways hyperreactivity. Only those workers with continuous exposure to linters, however, reacted with large mean declines in expiratory flow. Our analysis excluded the possibility that this observed difference was due to different personal or area dust exposure levels.

These findings point to atopy as a risk factor in the bronchoconstrictor response to cotton dust aerosol, and, by inference, a risk factor in byssinosis. There is therefore a need to investigate atopy, particularly as that variable may interact with dust exposure, in cotton textile mills.

We thank the Buckeye Crushing Division of the Procter and Gamble Company for providing mill space and employee time for the conduct of this study. 


\section{References}

${ }^{1}$ McKerrow CB, McDermott M, Gilson JC, Schilling RSF. Respiratory function during the day in cotton workers: a study in byssinosis. Br J Ind Med 1958;15:75-83.

2 Barnes R, Simpson GR. Ventilatory changes on exposure to cotton dust. Med J Aust 1968;1:897-900.

${ }^{3}$ Brown DF, Piccolo B, Tripp VW, Parnell CB Jr. Chemical composition of dusts from cottonseed oil mills. J Am Oil Chem Soc 1977;54:255-8.

${ }^{4}$ Noweir MH, El-Sadek Y, El-Dakhakhny AA. Exposure to dust in the cottonseed oil extraction industry. Arch Environ Health 1968;19:99-102.

${ }^{5}$ Simpson GR, Barnes R. Cotton dust exposure during lint removal. Arch Environ Health 1968;17:807-10.

- US Department of Health, Education and Welfare. Occupational exposure to cotton dust: criteria for a recommended standard. Washington DC: US Government Printing Office, 1974. (HEW publication No (NIOSH) 75-118.)

7 US Department of Labor. Occupational exposure to cotton dust: final mandatory occupational safety and health standards. Federal Register, 23 June 1978, part III. 1978:27350-418.

${ }^{8}$ Schilling RSF, Vigliani EC, Lammers B, Valic F, Gilson JC. A report on a conference on byssinosis. In: Proceedings of the 14th International Conference on Occupational Health, Madrid, 1963. Excerpta Medica, Int Congr Series, 1963;62:137-44.

- Merchant JA, Lumsden JC, Kilburn KH, et al. Dose response studies in cotton textile workers. JOM 1973; $15: 222-30$.

${ }^{10}$ Fox AJ, Tombleson JBL, Watt A, Wilkie AG. A survey of respiratory disease in cotton operations. Part II. Symptoms, dust estimations, and the effect of smoking habit. Br J Ind Med 1973;30:48-53.

${ }^{11}$ Berry G, Molyneux MKB, Tombleson JBL. Relationships between dust level and byssinosis and bronchitis in Lanchashire cotton mills. Br J Ind Med 1974;31:18-27.

12 Prindle B. The microbiology of textile fibers (cotton). Textile Res 1934;5:11-31.

${ }^{13}$ Kory RC, Callahan R, Boren HC, Syner JC. The Veterans Administration-Army cooperative study of pulmonary function. I: Clinical spirometry in normal men. $A m \boldsymbol{J}$ Med 1961;30:243-58.

${ }^{14}$ Smith JR, Kory RC. Laboratory aids in investigating pulmonary diseases. In: Baum GL, ed. Textbook of pulmonary diseases. Boston, Massachusetts: Little, Brown, 1965:25.

${ }^{15}$ Rossiter CE, Weill H. Ethnic differences in lung function: evidence for proportional differences. Int $J$ Epidemiol $1974 ; 3: 55-8$.

${ }^{16}$ Speed FM, Hocking RR, Hackney OP. Methods of analysis of linear models with unbalanced data. $\mathrm{J} \mathrm{Am}$ Statistical Assoc 1978;73:105-10.

17 Jones RN, Carr J, Glindmeyer H, Diem J, Weill H. Respiratory health and dust levels in cottonseed mills. Thorax 1977;32:281-6.

${ }^{18}$ Cayton HR, Furness G, Maitland HB. Studies on cotton dust in relation to byssinosis. Part II. Skin tests for allergy with extracts of cotton dust. $\mathrm{Br} J$ Ind Med 1952; 9:186-96.

19 Voisin C, Jacob M, Furon D, Lefebre J. Aspects cliniques et allergologiques des manifestations asthmatiques observées chez 114 ouvriers de filatures de coton. Poumon Coeur 1966;22:529-35.

${ }^{20}$ Popa V, Gavrilescu N, Preda N, Teculescu D, Plescias M, Cirstea M. An investigation of allergy in byssinosis: sensitisation to cotton, hemp, flax, and jute antigens. Br J Ind Med 1969;26:101-8. 